\title{
UNA HUELLA DE ROGIER VAN DER WEYDEN EN LA OBRA DE BERNART DE ARAS, "PINTOR VECINO DE LA CIUDAT DE HUESCA"*
}

\author{
POR \\ DIDIER MARTENS \\ Université Libre de Bruxelles \\ Faculté de Philosophie et Lettres
}

En 1461, el pintor aragonés Bernart de Aras recibe el encargo de realizar un retablo para la pequeña iglesia de Pompién (Huesca). Terminado en 1463, este retablo, que se mantenía todavía en su emplazamiento original en 1936 y del que una parte se conserva actualmente en el Museu Nacional d'Art de Catalunya en Barcelona, presentaba, en la tabla central, una Virgen entronizada con el Niño. Estas dos figuras no constituyen una creación del artista, sino que las tomó de una obra famosa de Rogier van der Weyden (1399/1400-1464): la Madona Durán, hoy conservada en el Museo Nacional del Prado. Esta tabla del pintor bruselense era, por lo tanto, ya conocida en la Península Ibérica en 1461-1463, es decir, en vida del artista.

Palabras claves: Bernart de Aras; Maestro de los Luna; Pompién; Rogier van der Weyden.

In 1461, the Aragonese painter Bernart de Aras was commissioned to paint an altarpiece for the small church of Pompién (Huesca). This altarpiece, completed two years later, could still be seen in its original location in 1936. Today, only four panels from the retable are preserved in the storerooms of the Museu d'Art de Catalunya in Barcelona. The central panel consists of a Madonna Enthroned with Child. Both of these figures clearly reflect the artist's familiarity with the Madonna Durán, one of Rogier van der Weyden's (1399/ 1400-1464) most famous pictures, now hanging in the Museo Nacional del Prado in Madrid. Therefore, it can be claimed that Rogier's work was already known in Spain during his lifetime.

Key words: Bernart de Aras; Master of the Luna; Pompién; Rogier van der Weyden.

* Es para mí un agradable deber el agradecer aquí a quienes me han ayudado en la preparación de este estudio: en Barcelona, Eva Franquero y Rosa Manote; en Huesca, María de la Paz Cantero Paños; en Zaragoza, Manuel del Diego Invernón, María del Carmen Lacarra Ducay, Pedro Lorente Lorente y Carmen Morte García. Mi manuscrito se ha beneficiado de las observaciones de Anna Maria Coderch (Fribourg, Suiza), Jacques de Landsberg, Thierry Lenain, François-René Martens y Monique Renault (Bruselas). Finalmente, estoy particularmente en deuda con Marta Negro Cobo (Burgos), que ha traducido mi texto al español. 


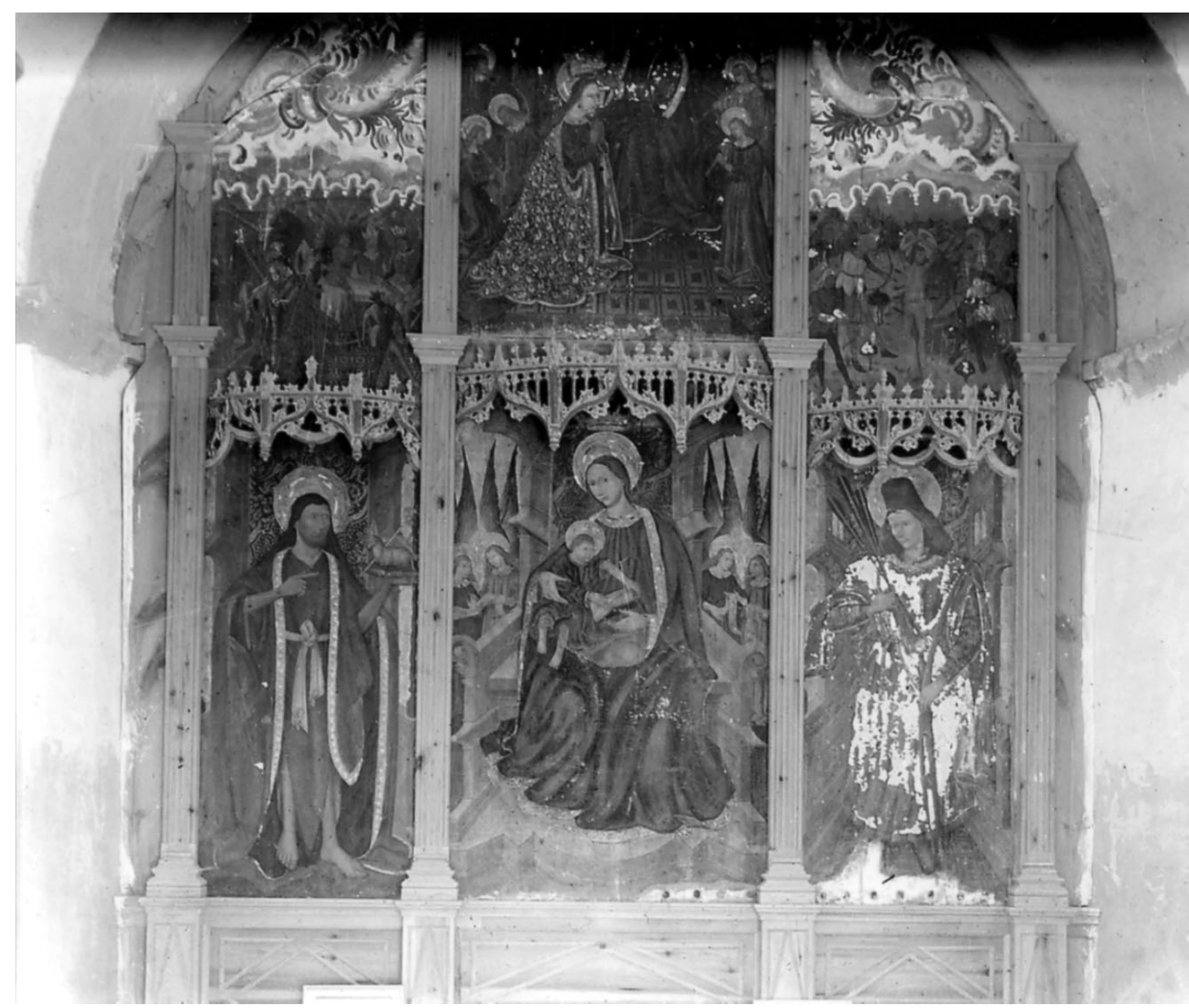

Fig. 1. Bernart de Aras: Retablo de Pompién antes de 1936 (cliché A. Mas, Barcelona).

Los historiadores de arte consideran hoy en día de forma unánime a Berna(r)t de Aras (Daras, Darias, de Ara) como una figura clave en la historia de la pintura aragonesa del siglo XV. No obstante, su nombre ha entrado tardíamente en la literatura científica. El redescubrimiento del artista se produjo en dos fases. En 1941, en los años centrales de la Segunda Guerra Mundial, Chandler Rathfon Post propuso atribuir a una misma mano dos retablos pintados: el dedicado a la Virgen, de la antigua iglesia de Pompién (Castillo de Pompién, Pompién Muzo) y el de san Vicente, del hospital de Nuestra Señora de la Esperanza en Huesca ${ }^{1}$. Actualmente ambos se encuentran fragmentados.

Del retablo de Pompién se conservan cuatro tablas en los almacenes del Museu Nacional d'Art de Catalunya en Barcelona: la Coronación de la Virgen, la Degollación de san Juan Bautista, un San Sebastián de pie y el Martirio de san Sebastián ${ }^{2}$. El conjunto monumental, que medía más de tres metros de altura, estaba presidido por una Virgen entronizada con el Niño entre cuatro ángeles, hoy desaparecida, pero conocida gracias a una fotografía anterior a 1936 (fig. 1), año

${ }^{1}$ C. R. Post, A History of Spanish Painting, VIII, 1: The Aragonese School in the Late Middle Ages, Cambridge (Mass.), 1941, pp. 380-387.

${ }^{2}$ Barcelona, MNAC, n. ${ }^{\circ}$ inv. 122461, Coronamiento de la Virgen, $147 \times 112,5 \mathrm{~cm}$;.$^{\circ}$ inv. 122462, Degollación de san Juan Bautista, $103 \times 78,2$ cm; n. ${ }^{\circ}$ inv. 122463, Martirio de san Sebastián, $103 \times 78$ cm; n. ${ }^{\circ}$ inv. 122464, San Sebastián, $157 \times 78,5 \mathrm{~cm}$ (información proporcionada por Rosa Manote, 18 febrero 2004). Vid. últimamente sobre este retablo, A. Naval Mas, Patrimonio emigrado, Huesca, 1999, pp. 112-114. 
en el que fue retirado y desmembrado. Del segundo retablo citado, el de san Vicente, el Museo de Huesca posee la figura de pie del diácono mártir (fig. 2), así como la tabla del Calvario que originalmente lo coronaba ${ }^{3}$.

Post bautizó al autor de los dos retablos como "Maestro de Pompién" y supuso que debía trabajar en Huesca. Es en esta misma ciudad donde se encontraba el hospital de Nuestra Señora de la Esperanza. En cuanto a Pompién, hoy un despoblado, se localiza en los alrededores inmediatos de Huesca, apenas a seis kilómetros hacia el sur' ${ }^{4}$.

Los autores más recientes han aceptado sin reservas el enlace estilístico realizado por el historiador de arte norteamericano ${ }^{5}$. El parentesco estilístico entre los dos retablos es manifiesto. Los ángeles que rodean a la Virgen entronizada de Pompién (fig. 3) son similares a los que portan los atributos de san Vicente en la tabla del Museo de Huesca y constituyen como una firma del artista. Presentan el mismo rostro con nariz saliente y mentón puntiagudo, la frente bien despejada con el cabello cayendo en abundantes bucles sobre los hombros y los ropajes animados por pliegues verticales.

La hipótesis de Post según la cual el artista habría trabajado en Huesca se verá también confirmada gracias a documentos conservados en los archivos. A diferencia de otros pintores de nombre prestado, como los maestros de la Leyenda de santa Lucía y de la Leyenda de santa Úrsula o el del Retablo de san Bartolomé, que, después de un siglo, resisten a las tentativas de identificación 6 , la etiqueta de "Maestro de Pompién", aplicada de forma convencional a un grupo de obras y basada en rasgos de estilo, pudo felizmente sustituirse al poco tiempo por una identitad clara y bien documentada. Descubierto en 1941, el anónimo pintor adquirió seis años más tarde un verdadero perfil histórico. En 1947, el archivero de Huesca Ricardo del Arco dio a conocer en esta misma revista el contrato del retablo de Pompién, conservado en el Archivo Histórico Provincial ${ }^{7}$. Será este contrato el que nos facilite el nombre del pintor: Bernart de Aras.

\footnotetext{
${ }^{3}$ Huesca, Museo de Huesca, n. ${ }^{\circ}$ inv. 107, San Vicente, $164 \times 114 \mathrm{~cm}$; n. ${ }^{\circ}$ inv. 108, Calvario, 165,5 × $115 \mathrm{~cm}$. Vid. últimamente sobre este retablo, M. LaCARra Ducay, en Signos. Arte y cultura en el Alto Aragón medieval (cat. de exp.), Jaca, Catedral / Museo Diocesano y Huesca, Sala de Exposiciones / Sala Carderera, 1993, p. 434.

${ }^{4}$ Pompién es actualmente un despoblado dependiente del municipio de Monflorite-Lascasas (A. ZAPATER, Aragón pueblo a pueblo, Zaragoza, 1986, VI, p. 1423).

5 Vid. por ejemplo J. Gudiol Ricart, Ars Hispanice, IX: Pintura gótica, Madrid, 1955, p. 305; J. CAmón AzNAR, Summa Artis, XXII: Pintura medieval española, Madrid, 1966, p. 475; J. Gudiol RicART, Pintura medieval en Aragón, Zaragoza, 1971, pp. 57 y 82-83; F. MAÑAs BALlestín, Pintura gótica aragonesa, Zaragoza, 1979, p. 144; M. LACARRA DuCAY, “Pintura gótica en el Alto Aragón”, en Signos. Arte y cultura en el Alto Aragón medieval (cat. de exp.), Jaca, Catedral / Museo Diocesano y Huesca, Sala de Exposiciones/ Sala Carderera, 1993, pp. 181-182. He dejado de lado dos hipotéticas atribuciones de Post al Maestro de Pompién, que no han sido consideradas por los autores posteriores (Post, op. cit., pp. 382-387).

6 Vid., para el Maestro de la Leyenda de santa Úrsula y para el de la Leyenda de santa Lucía, una tentativa de identificación reciente, aunque parece extremadamente hipotética: A. JANSSENS, "De Meesters van de Lucia- en de Ursulalegende. Een poging tot identificatie", Handelingen van het Genootschap voor Geschiedenis, 141, 2004, pp. 278-314. Vid. para el Maestro del Retablo de san Bartolomé, R. Budde y R. Krischel (ed.), Genie ohne Namen. Der Meister des Bartholomäus-Altares (cat. de exp.), Colonia, Wallraf-Richartz-Museum, 2001. Los organizadores de esta exposición prudentemente han dejado de lado la cuestión de la identidad del pintor.

7 Huesca, Archivo Histórico Provincial, Protocolo n. ${ }^{\circ}$ 2546, notario Tomás Bonifante, 1461, fol. 1-5. R.DEL Arco y Garay, "Nuevas noticias de artistas altoaragoneses", Archivo español de Arte, 20, 1947, p. 219. Vid., para una edición comentada del contrato, idem, "Documentos inéditos del arte aragonés", Seminario de Arte aragonés, 4, 1952, pp. 56-58; M. LACARRA DuCAY, "Sobre dibujos preparatorios para retablos de pintores aragoneses del siglo XV”, Anuario de Estudios medievales, 13, 1983, pp. 555-557, 573-574. El hallazgo del contrato será recogido por C. R. Post, A History of Spanish Painting, X: The Early Renaissance in Andalusia, Cambridge (Mass.), 1950, pp. 399-402.
}

AEA, LXXXI, 321, ENERO-MARZO 2008, 1-16, ISSN: 0004-0428 


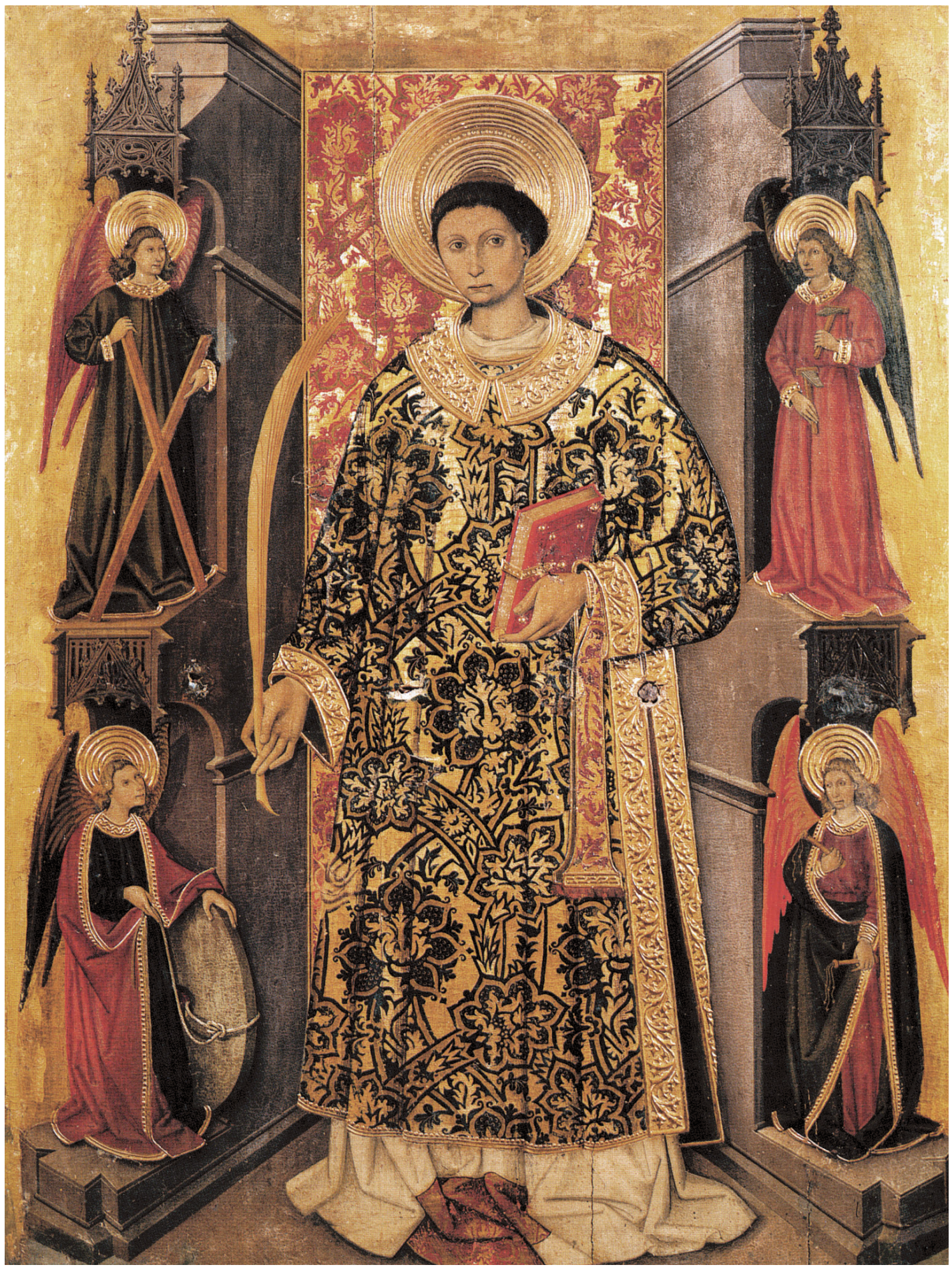

Fig. 2. Bernart de Aras: San Vicente; Huesca, Museo de Huesca (cliché museo de Huesca). 
Bernart de Aras ha dejado numerosos rastros en la documentación histórica. Atestiguado entre 1433 y 1472 principalmente en Huesca pero también en Zaragoza, parece haberse especializado con cierto éxito en la pintura de retablos ${ }^{8}$. Los documentos mencionan seis, destinados a iglesias de Huesca y sus alrededores: Barbastro, Apiés, Pompién, Embún y Ayera. A este conjunto de obras se añade otro retablo, realizado para una iglesia de Tardienta en colaboración con un artista establecido en Huesca, Pedro de Zuera. Excepto el retablo de Pompién y quizás también el pintado con Pedro de Zuera ${ }^{9}$, ninguna de las obras documentadas de Bernart de Aras ha llegado hasta nosotros.

El 26 de enero de 1461, el maestro se compromete ante notario a realizar un retablo para la iglesia de San Juan Bautista de Pompién. El comitente de la obra es el señor del lugar Gilbert Redón. Además del programa iconográfico y de algunas precisiones en cuanto a los materiales que el artista debía emplear, el contrato recoge, según una costumbre atestiguada en numerosas ocasiones en Aragón, una "muestra", un boceto dibujado del encargo (fig. 4).

Se especifica que el conjunto llevaría un sagrario ornamentado con las figuras de Cristo, de la Virgen y de san Juan Evangelista ("aya en medio de la custodia huna Piedat, e de hun cabo San Juan e del hotro Santa Maria"). La predela se decoraría con efigies de santos y santas: Pedro, Vicente, Lorenzo, Quiteria, Águeda y Catalina ("en la seis estaciones del piet [...] ayan de meter Sant Pedro, Sant Lorenz, e Sant Vincent, Santa Quiteria, Santa Agueda, Santa Quatallina"). La tabla central del retablo debía representar a la Virgen entronizada con el Niño rodeada de ángeles ("a de aver en la pieza de medio la Virgen Maria con su Fillo en el brazo aconpanyada de angeles entorno della, ella posada en una gentil cadira"). La Virgen estaría flanqueada por las figuras de san Juan Bautista y san Sebastián ("a de aver al costad o a la dita ymagen en la huna ystoria mayor la ymatgen de senyor San Juan Bautista e de la hotra part la ymatgen de senyor Sant Sebastian"). El segundo piso lo ocuparía una Coronación de la Virgen ("a de aver en somo de la ymagen de la Virgen Maria la coronazion como coronava a la Virgen Marya nuestro senyor Ihesu Christo"), situado entre escenas de la vida de los santos Juan Bautista y Sebastián. En la época de la firma del contrato, la selección de estas escenas todavía no se había concretado. Se precisa además que el episodio elegido de la vida del Precursor debía de ser del gusto de Gilbert Redón ("a de aver en somo de senyor Sant Juan huna estoria del dito santo aquella que al senyor del conzello sera bien vista e ansima [a]ver hotra estoria de la hotra parte de senyor Sant Sebastian"). El 27 de febrero de 1463, Bernart de Aras declara haber recibido la totalidad de las cantidades debidas.

No puede haber ninguna duda en cuanto a la identificación del retablo aludido en este contrato con el que se encontraba, hasta el inicio de la Guerra Civil, en la parroquia de Pompién, una iglesia románica de una sola nave donde presidiría el presbiterio ${ }^{10}$. La descripción del programa iconográfico y el boceto del contrato concuerdan perfectamente con la obra del negativo del Archivo Mas.

No obstante, entre 1463 y 1936, el retablo sufrió diversas transformaciones, consecuencias de una o varias restauraciones que cada vez han sido también adaptaciones al gusto de la época.

\footnotetext{
${ }^{8}$ Lacarra Ducay, op. cit., 1983, pp. 555-556; F. Balaguer SÁnchez, "El pintor Bernat de Ara”, Argensola, 104, 1990, pp. 249-250; LaCARra DuCAY, "Pintura gótica en el Alto Aragón”, op. cit., 1993, pp. 181-182.

9 Podría tratarse del retablo conservado en el Museo Diocesano de Huesca procedente de Tardienta. Vid., sobre esta obra, M. C. Lacarra Ducay y C. Morte García, Catálogo del Museo Episcopal y Capitular de Huesca, Zaragoza, 1984, pp. 75-78.

10 Vid. sobre esta iglesia, hoy en día cerrada al culto y de propiedad privada, R. DEL ARCO y GARAY, Catálogo monumental de España: Huesca, Madrid, 1942, pp. 166-169; A. NAVAL Mas y J. NAVAL Mas, Inventario artístico de Huesca y su provincia, II: Partido judicial de Huesca (Banaries-Yequeda), Madrid, 1980, pp. 172-174; J. L. ArAmENDíA, El Románico en Aragón, IV: Cuencas del Isuela y Gállego, Zaragoza, 2002, pp. 21-23.
}

AEA, LXXXI, 321, ENERO-MARZO 2008, 1-16, ISSN: 0004-0428 


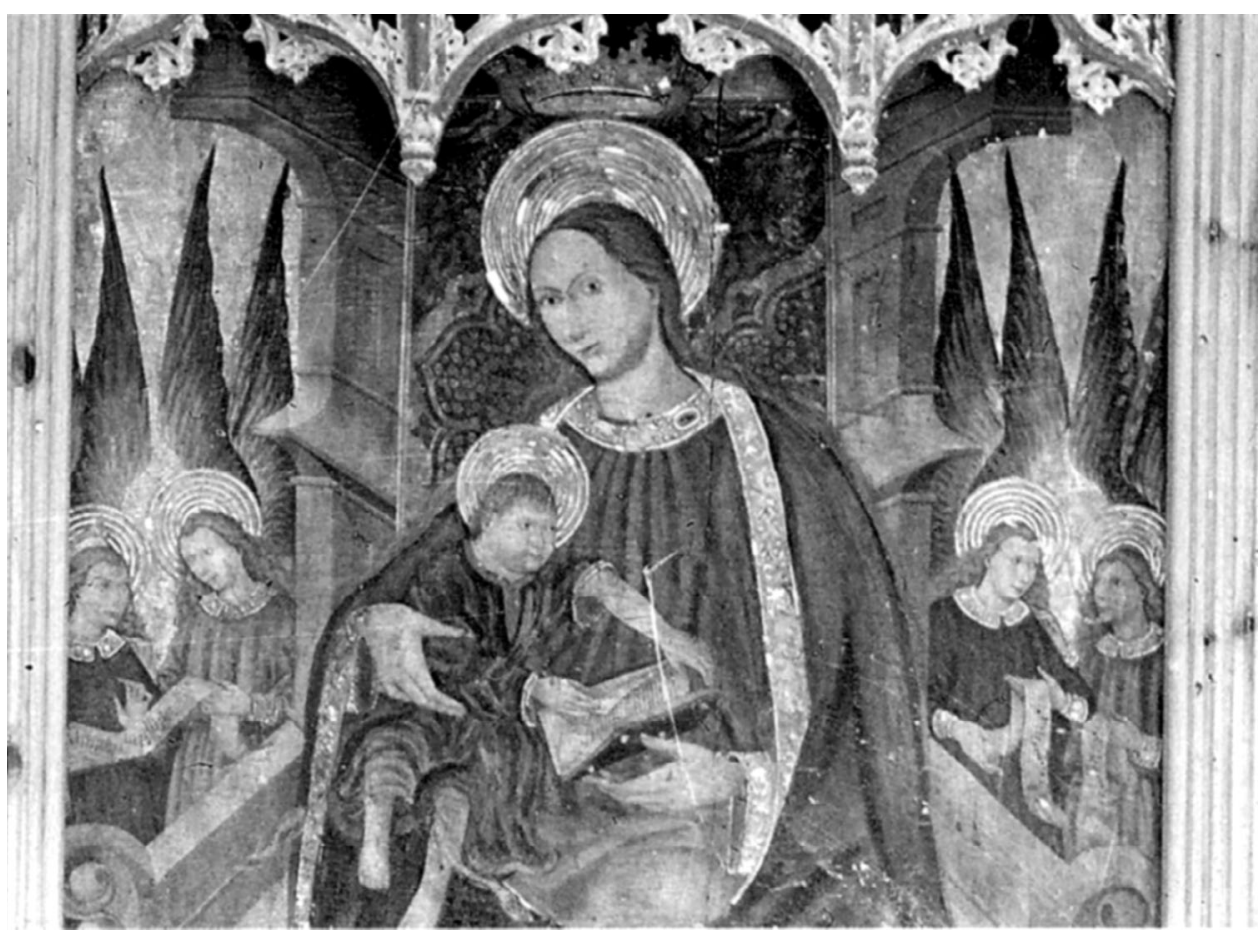

Fig. 3. Bernart de Aras: Virgen entronizada (detalle); paradero actual desconocido (cliché A. Mas, Barcelona).

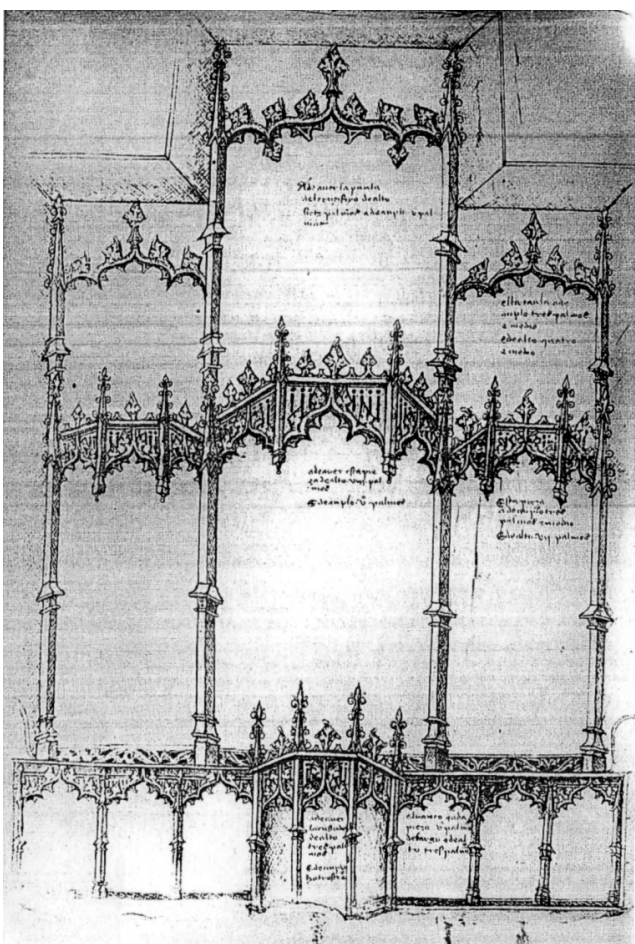

Fig. 4. Bernart de Aras (?): boceto que acompaña el contrato para el retablo de Pompién; Huesca, Archivo Histórico Provincial. 
El conjunto gótico original adquirió así una apariencia que le aproximaba a los siglos XVIII o XIX. Las jambas con pináculos fueron reemplazadas por pilastras acanaladas de gusto clásico.

El guardapolvo primitivo fue sustituido por un marco plano, que aseguraba el anclaje del retablo a la pared del ábside. Los doseles que coronaban las dos escenas narrativas del piso superior fueron eliminados y en su lugar se pintaron dos volutas simétricas de estilo rococó, que reforzaban la unidad visual del conjunto. La predela fue desmontada y el sagrario debió de ser reemplazado por otro de estilo barroco o clásico. Finalmente, el manto de la Virgen y la ropa del Niño Jesús fueron repintados (fig. 5). El nuevo drapeado con pliegues redondeados enmascara completamente el dibujo original de Bernat de Aras. Aparentemente, las dos figuras debían de estar deterioradas y un restaurador (¿el mismo que pinta las volutas rococó?) no habría estimado necesario respetar los plegados aplastados y quebrados tan característicos del siglo XV. Prefirió actualizar la imagen dotando a las figuras de un drapeado más flexible, modelado por un juego contrastado de luces y sombras casi barroco.

Originalmente, el manto de la Virgen parece haber estado ornamentado con motivos de brocado, de los que se pueden apreciar todavía algunos restos a la altura de la rodilla izquierda. María habría llevado el mismo manto abigarrado que en la Coronación de la Virgen. Tal profusión ornamental, típica del Gótico final aragonés, no debió de ser tampoco del gusto del restaurador, quien habría puesto especial empeño en modernizar la tabla principal del retablo.

Combinando las informaciones facilitadas por el contrato, el boceto y la fotografía del Archivo Mas, podemos hacernos una idea precisa de la disposición original de las tablas del retablo. En la predela, de la que en 1942, según Ricardo del Arco, la iglesia conservaba todavía cuatro paneles ${ }^{11}$, los santos y santas estaban separados y dispuestos a ambos lados del sagrario. Conforme al uso heráldico, los santos ocuparían probablemente el lado izquierdo y las santas el derecho ${ }^{12}$. En cuanto a la efigie de san Juan Bautista, se situaba a la izquierda de la tabla central. Esta particular disposición se explica por el hecho de que, según los términos del contrato de 1461, la iglesia estaba dedicada en esos momentos al Bautista ${ }^{13}$. Es por lo tanto a este último al que naturalmente correspondía, dentro del sistema jerarquizado de imágenes que era entonces el retablo gótico aragonés, el lugar más eminente, justo después del panel central ocupado, como era debido, por el grupo de la Virgen con el Niño. San Juan estaba colocado "a la derecha del Señor", una posición que ponía en evidencia su elección ${ }^{14}$.

Además, señalaba con la mano derecha no sólo al Cordero de Dios, sino también al Niño, situado exactamente en el prolongamiento de su índice. La identificación entre el Cordero y el Niño era así manifiesta ante los fieles.

11 Del Arco y Garay, op. cit., 1942, p. 168.

12 D. Martens, “Autour des retables du jubé de l'église des chartreux de Cologne: lumière réelle et lumière fictive dans la peinture flamande et allemande de la fin du Moyen Âge", Wallraf-Richartz-Jahrbuch, 57, 1996, pp. 73-77; idem, "Le Maître aux Madones joufflues. Essai de monographie sur un anonyme brugeois du XVIème siècle", WallrafRichartz-Jahrbuch, 61, 2000, p. 113.

13 En el siglo XIX, según el conocido Diccionario geográfico-estadístico-histórico de España y sus posesiones de Ultramar de Pascual Madoz (Madrid, 1845-1850), la iglesia de Pompién estaba dedicada a Santa Ana (P. Madoz, Diccionario geográfico-estadístico-histórico de Aragón: Huesca, Zaragoza, 1985, p. 295). Por contra, en una descripción de 1792 se menciona como consagrada a "Nuestra Señora de los Ángeles" (Descripción topográfica de la Ciudad de Huesca y todo su partido en el Reyno de Aragón, por el Dr. D. Pedro Blecua y Paul, Año 1792, Zaragoza, 1987, p. 148). ¿Es una casualidad, si esta segunda advocación se corresponde perfectamente con la representación de la tabla central del retablo? Nada se sabe de cuándo desapareció el patrocinium de san Juan Bautista.

14 M.-L. Lievens-De WaEgh, "Quelques symboles fondamentaux chez les 'Primitifs flamands"”, en Miscellanea Henri Pauwels (Bulletin des Musées Royaux des Beaux-Arts de Belgique, 38-40, 1989-1991, n. ${ }^{\circ}$ 1-3), Bruselas, 1992, p. 149 .

AEA, LXXXI, 321, ENERO-MARZO 2008, 1-16, ISSN: 0004-0428 


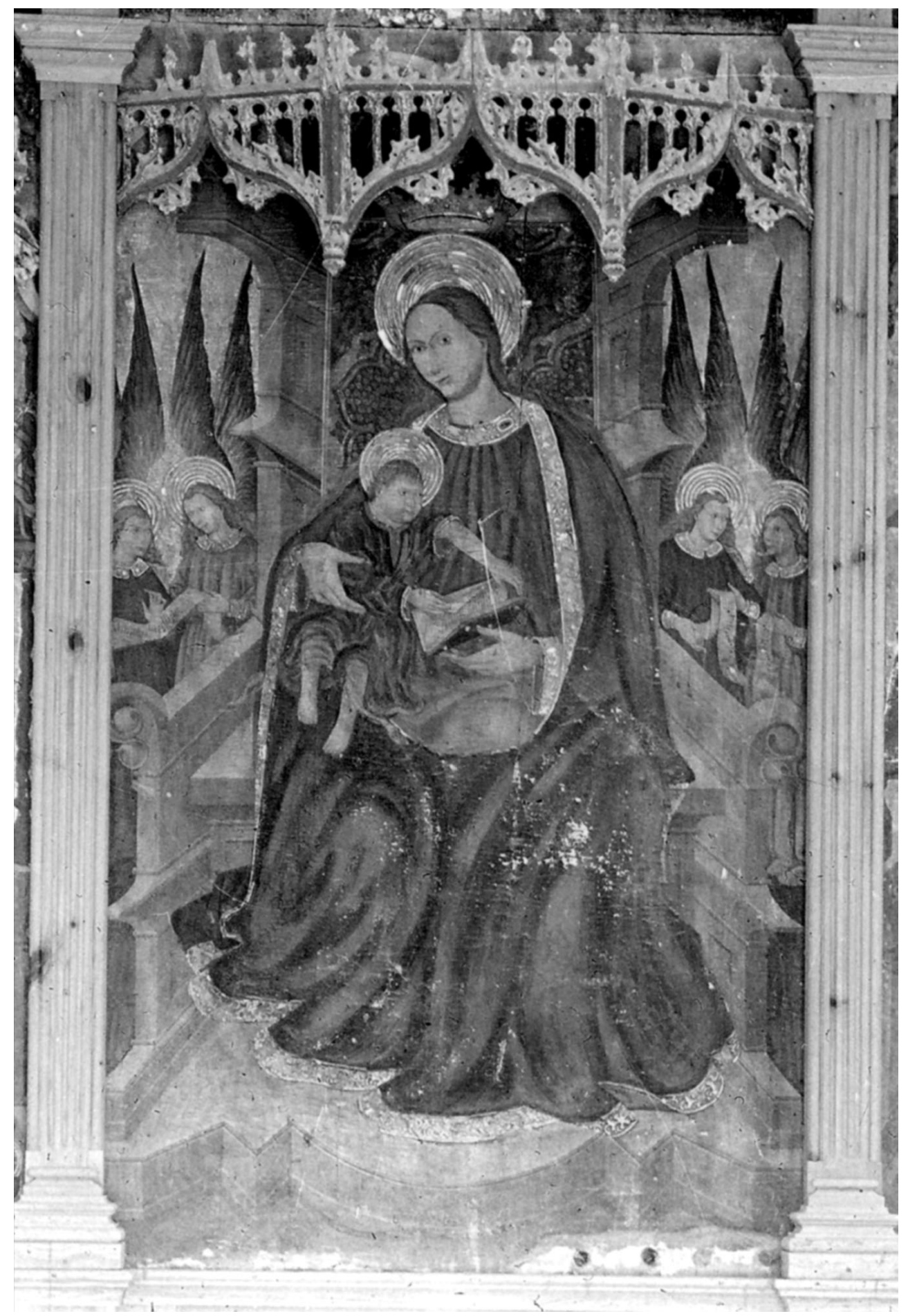

Fig. 5. Bernart de Aras: Virgen entronizada; paradero actual desconocido (cliché A. Mas, Barcelona). 
Si la forma general del retablo, el estilo de la pintura y la disposición de las figuras no desentonan nada en el contexto artístico de la pintura aragonesa de finales de la Edad Media, por el contrario, el modelo elegido por el artista para la tabla central es cuando menos inesperado. No me parece que se haya señalado hasta ahora que Bernart de Aras se inspiró en una obra del célebre pintor Rogier de le Pasture, más conocido en España por su nombre flamenco Rogier van der Weyden (Tournai c.1399-Bruselas 1464): la Madona Durán, llamada también la Madona en rojo (fig. 6), que se conserva en la actualidad en el Prado ${ }^{15}$.

La composición del maestro de Tournai es de una gran sencillez. María, a la que se presta a coronar un ángel, sostiene sobre sus rodillas al Niño Jesús. El recién nacido está representado mientras arruga con su mano derecha las páginas de un gran manuscrito, lo que pone en evidencia su humanidad. La Virgen porta un largo manto rojo y un vestido también de color rojo. Está sentada en una hornacina gótica, reposando sus pies sobre una ménsula semicircular, que sobresale de la pared vertical a la que el espectador tiende a identificar como la tabla misma, resultando para el grupo un efecto ilusionista de presencia real.

Aunque la Madona entronizada del retablo de Pompién no es conocida en la actualidad, salvo por la fotografía, no es difícil apreciar en esta pintura la impronta de la Madona Durán. La figura del Niño, la inclinación hacia la izquierda de la cabeza de la Virgen, la compostura de sus manos y la caída del manto sobre su rodilla izquierda han sido tomadas del modelo rogeriano. Del mismo modelo procede el plegado del vestido de María, que se presenta bajo la forma de cañas radiantes desde el cuello. En su estado documentado por la fotografía, el drapeado del manto difiere del concebido por el maestro de Tournai. En su tentativa de adecuar la tabla al gusto de su época, el restaurador moderno ha borrado probablemente una parte del vínculo con el arte de Rogier van der Weyden.

Aunque la huella de Van der Weyden se reconozca perfectamente, sería injusto tachar a Bernart de Aras de servil. Más bien al contrario se constata como ha adaptado la Madona Durán a las tradiciones locales, realizando una auténtica "inculturación" aragonesa de la fuente flamenca. Así, ha dotado a María y al Niño de nimbos en relieve, constituidos por varios anillos concéntricos, ahí donde Rogier, fiel al espíritu del nuevo naturalismo flamenco, ha renunciado a cualquier aureola. Además ha provisto al manto y a la ropa de la Virgen de una cenefa dorada, también en relieve. Sabemos cuánto apreciaba el público aragonés estos elementos aplicados. Producían una ilusión de presencia real obtenida por medios que no son intrínsecamente pictóricos y que remiten más bien al arte del bajo-relieve. El contraste con el saliente parcial, fuera de la tabla, de la figura mariana en la Madona Durán es claro. Aquí el efecto es el resultado de medios específicamente pictóricos.

Finalmente, Bernart de Aras ha reemplazado los ojos bajos y semi-cerrados de la Madona Durán por unos grandes ojos abiertos, que buscan cruzar su mirada con la del espectador. En el retablo de Pompién, María observa al fiel, siguiendo una tradición bizantina que toma sus raíces en el arte romano de Bajo Imperio ${ }^{16}$ y que se mantiene en Aragón hasta finales del siglo XV. Estamos lejos de la expresión soñadora, más interior que, en el mismo momento, los pintores del Norte gustaban dar a sus Madonas, incluso cuando copiaban un modelo oriental ${ }^{17}$.

${ }^{15}$ Madrid, Museo Nacional del Prado, n. ${ }^{\circ}$ inv. 2722, $100 \times 52 \mathrm{~cm}$. Vid., sobre esta obra, D. DE Vos, Rogier van der Weyden. Het volledige cuvre, Amberes, 1999, n. ${ }^{\circ}$ 5; A. Сhâtelet, Rogier van der Weyden. Problèmes de la vie et de l'ceuvre, Estrasburgo, 1999, n. ${ }^{\circ}$ AC 47; P. Silva Maroto, Museo del Prado. Guía. Pintura flamenca de los siglos XV y XVI, Madrid, 2001, pp. 82-83. 2003.

16 Vid., sobre esta tradición, R. Tefnin, Le regard de l'image. Des origines jusqu'à Byzance, Gante/Amberes,

17 Vid., sobre el tema, H. Belting, Bild und Kult. Eine Geschichte des Bildes vor dem Zeitalter der Kunst, Múnich, 1990, p. 491.

AEA, LXXXI, 321, ENERO-MARZO 2008, 1-16, ISSN: 0004-0428 
Típicamente aragonés es también el trono de María con dosel. No obstante, podemos preguntarnos si en el detalle del basamento semicircular Bernart de Aras no se ha inspirado en la ménsula de forma análoga sobre la que la Madona Durán reposa los pies. El gusto por las superficies ornamentales, característica de los pintores aragoneses a lo largo de todo el siglo XV, aparece en el paño del brocado, decorado con motivos vegetales, que ha tomado el sitio de la superficie desnuda del fondo de la hornacina rogieriana (en la actualidad, en la tabla del Prado, esta pared cóncava está disimulada por unas sombras opacas, que no son originales ${ }^{18}$ ). Hemos visto que, probablemente, el manto de la Virgen, tal y como lo había pintado Bernart de Aras, estaba también recubierto de motivos ornamentales. Además, el enlosado que se aprecia de un lado y del otro del trono está representado casi sin perspectiva, dando la impresión de un plano decorativo vertical, paralelo a la tabla misma. A la austeridad de las superficies monócromas de la Madona en rojo, el maestro de Huesca opone una riqueza ornamental heredera del gótico internacional.

Es este gusto por el ornamento el que permite comprender por qué Bernart de Aras no se ha preocupado en imitar los escorzos de su modelo. Van der Weyden ha compuesto el libro y la mano derecha de María de tal manera que parecen atravesar el espacio de la representación. En la tabla central del retablo de Pompién, al contrario, son casi paralelos al plano de la imagen. Esta voluntad del pintor aragonés de limitar los efectos de profundidad está acompañada por una búsqueda de la simetría decorativa, también ajena al arte de Rogier. Las dos parejas de ángeles, de un lado y otro del trono, se corresponden. Bernart de Aras ha modificado sutilmente la disposición del grupo rogieriano, para reforzar su adherencia formal a la superficie de la tabla. Del lado izquierdo, la cenefa del manto envuelve ahora el Niño y la rodilla derecha de María con un contorno de gran sencillez, un contorno que encuentra casi su simétrico en el lado derecho. El resultado es una configuración cerrada en forma de campana, mientras que la Madona en rojo se caracteriza por la neta orientación del grupo hacia la izquierda.

¿Cómo pudo Bernart de Aras inspirarse en la composición de Van der Weyden? ¿cómo la conoció? La hipótesis de un grabado, que viene inmediatamente a la mente del historiador de arte, puede ser fácilmente descartada. Aunque sea éste el medio por el cual, en general, los pintores aragoneses de finales de la Edad Media deben su conocimiento del arte del norte de Europa ${ }^{19}$, hace falta no obstante señalar que ningún grabado reproduciendo la composición de Van der Weyden ha sido identificado actualmente. Por otra parte, las composiciones de los grandes Primitivos flamencos no parece que fueran difundidas por grabados antes de la segunda mitad del siglo XVI, la época de Cornelis Cort y de los Wierix.

Es más probable que Bernart de Aras conociera a la Madona Durán por una copia pintada. La imagen fue efectivamente reproducida en numerosas ocasiones en la pintura ${ }^{20}$. Además, todo

18 J. R. J. van Asperen de Boer, J. Dijkstra y R. van Schoute, Underdrawing in Paintings of the Rogier van der Weyden and Master of Flémalle Groups (Nederlands Kunsthistorisch Jaarboek, 41, 1990), Zwolle, 1992, p. 235.

19 Vid., por ejemplo, sobre la influencia de los grabados de Schongauer sobre los pintores aragoneses, M. C. LACARra DucaY, "Influencia de Martin Schongauer en los Primitivos aragoneses", Boletín del Museo e Instituto Camón Aznar, 17, 1984, pp. 15-25.

20 Vid., sobre las copias suscitadas por la Madona Durán, R. A. КосH, “Copies of Roger van der Weyden’s Madonna in Red", Record of the Art Museum, Princeton University, 26, 1967, pp. 46-58; E. Bermejo MarTínez, La pintura de los Primitivos flamencos en España I, Madrid, 1980, pp. 112-114; M. P. Silva Maroto y M. Garrido, "Contribution du dessin sous-jacent à l'identification et à la connaissance des peintres hispano-flamands castillans", en Le dessin sous-jacent dans la peinture. Colloque IX, $12-14$ septembre 1991, Lovaina-la-Nueva, 1993, pp. 131-133; D. MARTENS, "Le rayonnement européen de Rogier de le Pasture (vers 1400-1464), peintre de la Ville de Bruxelles", Annales de la Société royale d'Archéologie de Bruxelles, 61, 1996, pp. 58-77; idem, "Un témoin méconnu de la peinture bruxelloise de la fin du Moyen Âge: le triptyque de saint Hippolyte au Musée des Beaux-Arts de Boston", Revue belge d'Archéologie et d'Histoire de l'Art, 79, 2000, pp. 74-79; A. SimON, Österreichische Tafelmalerei der Spätgotik. Der niederländische Einfluss im 15. Jahrhundert, Berlin, 2002, pp. 274-276. Vid. también la nota 22. 
indica que el original mismo se encontraba ya desde el siglo XV en la Península Ibérica, aunque oficialmente no reapareciera hasta en 1930, cuando fue legado al Prado por el coleccionista Pedro Fernández-Durán, que lo había adquirido en Madrid en 1899.

Esta temprana salida hacia España explicaría el por qué la composición rogieriana suscitó un número muy limitado de réplicas en los antiguos Países Bajos, réplicas que se distinguen por su escasa fidelidad. Al contrario, en la Península Ibérica son numerosas las obras del siglo XV y primera mitad del XVI que se inspiran en la Madona Durán. Aunque algunas sean verdaderos collages, combinando elementos provenientes de diferentes obras flamencas, otras pueden ser clasificadas como copias fieles. Esto es así, por ejemplo, en la tabla con las armas de los Mendoza y los Quiñones ${ }^{21}$ (fig. 7), que reproduce no sólo el marco de la hornacina, sino también el rostro de la Virgen de Van der Weyden, en una época en la que los pintores tenían por costumbre dotar a las figuras que copiaban de rostros tomados de su propio repertorio fisonómico.

La mayoría de las copias españolas de la Madona Durán pueden localizarse en Castilla, en particular en el círculo del Maestro de los Luna. No obstante, el retablo de Pompién y una tabla de la antigua colección madrileña Scholtz-Hermensdorff, atribuida tradicionalmente a un anónimo valenciano, el Maestro de Bonastre ${ }^{22}$, demuestran que el modelo flamenco no era desconocido en los territorios de la corona de Aragón. La "recepción" de la Madona Durán y su "inculturación" en tierras ibéricas constituyen, como se ve, una página de la historia del arte español en el sentido estricto del término.

Hasta hoy día se ha considerado a la Virgen entronizada del retablo de los Luna en la Catedral de Toledo como la más antigua copia datada de la Madona Durán ${ }^{23}$. El contrato se remonta al 21 de diciembre de $1488^{24}$. El pintor castellano ha tomado de Rogier el ángel con la corona y la peana semicircular del trono de María. La identificación de la fuente flamenca en la Virgen entronizada de Pompién obliga, de ahora en adelante, a considerar que la Madona Durán era ya conocida en la Península Ibérica desde 1461-1463, es decir, todavía en vida de su autor, que muere en 1464. Esta conclusión refuerza la hipótesis de que la tabla podría tener su origen en un encargo español, como otra obra de Van der Weyden, el tríptico de Miraflores, del que sabemos fue ofrecido en 1445 por el rey de Castilla Juan II a la Cartuja de Burgos. Dirk de Vos sugiere incluso que la Madona Durán ha sido el modelo de este mismo tríptico ${ }^{25}$.

Encontramos efectivamente, en cada una de sus tres tablas, el motivo del ángel con una corona en las manos, volando en el eje de simetría vertical de un arco gótico. Según de Vos, el comitente español del tríptico, muy probablemente el mismo Juan II, habría pedido expresamente al maestro de Tournai usar una fórmula de la que ya había podido apreciar el efecto en otra tabla flamenca, llegada con anterioridad a la Península: la Madona Durán.

21 Vid., sobre esta obra, Old Master Paintings. Including Pictures from the Gutzwiller and Bürgenstock Collections (cat. de subasta), Londres, Sotheby's, 11 diciembre 1996, n. ${ }^{\circ}$ 8. El terminus ante quem de 1479 sugerido para la combinación de las armas de los Mendoza y de los Quiñones parece difícilmente compatible con las características estilísticas de la obra, que dudaríamos en datar antes de 1500. Advertimos además que María se sitúa sobre un fondo negro, que ha debido de ser copiado de la Madona Durán en su estado "restaurado". Sólo la copia de Princeton ha conservado el recuerdo de la superficie cóncava de la hornacina primitiva.

22 Vid., sobre esta obra, MARTEns, op. cit., 1996, pp. 67-70; J. GÓMEZ FreChinA, en La clave flamenca en los Primitivos valencianos (cat. de exp.), Valencia, Museo de Bellas Artes, 2001, p. 191; idem, en La pintura gótica hispanoflamenca: Bartolomé Bermejo y su época (cat. de exp.), Barcelona (...), Museu Nacional d'Art de Catalunya (...), 2003, p. 207.

${ }^{23}$ Vid., sobre esta obra, B. Piquero López, en Ysabel, la Reina Católica. Una mirada desde la Catedral primada (cat. de exp.), Toledo, Catedral, 2005, n. ${ }^{\circ} 36$.

${ }^{24}$ Vid., para una edición comentada de este contrato, J. B. SoBré, Behind the Altar Table. The Development of the Painted Retable in Spain 1350-1500, Columbia, 1989, pp. 318-331.

${ }^{25}$ DE Vos, op. cit., p. 191.

AEA, LXXXI, 321, ENERO-MARZO 2008, 1-16, ISSN: 0004-0428 


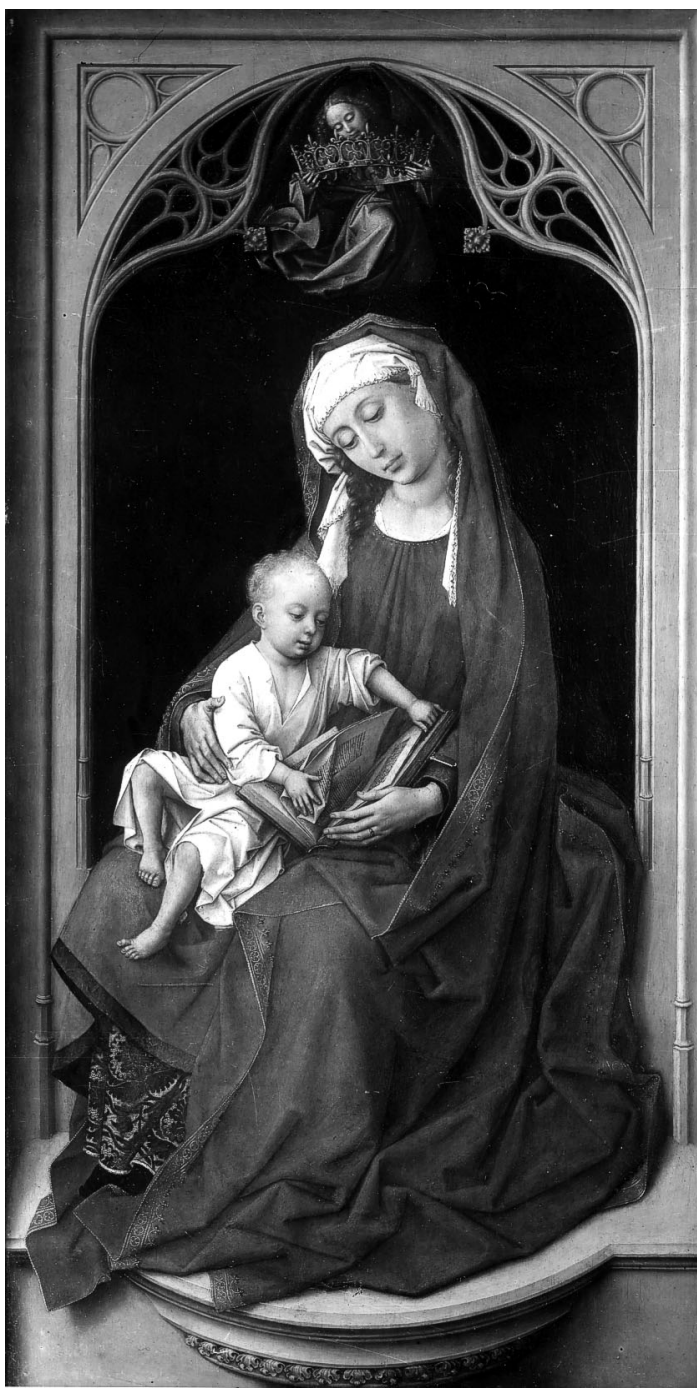

Fig. 6. Rogier Van der Weyden: Madona Durán; Madrid, Museo Nacional del Prado (cliché museo).

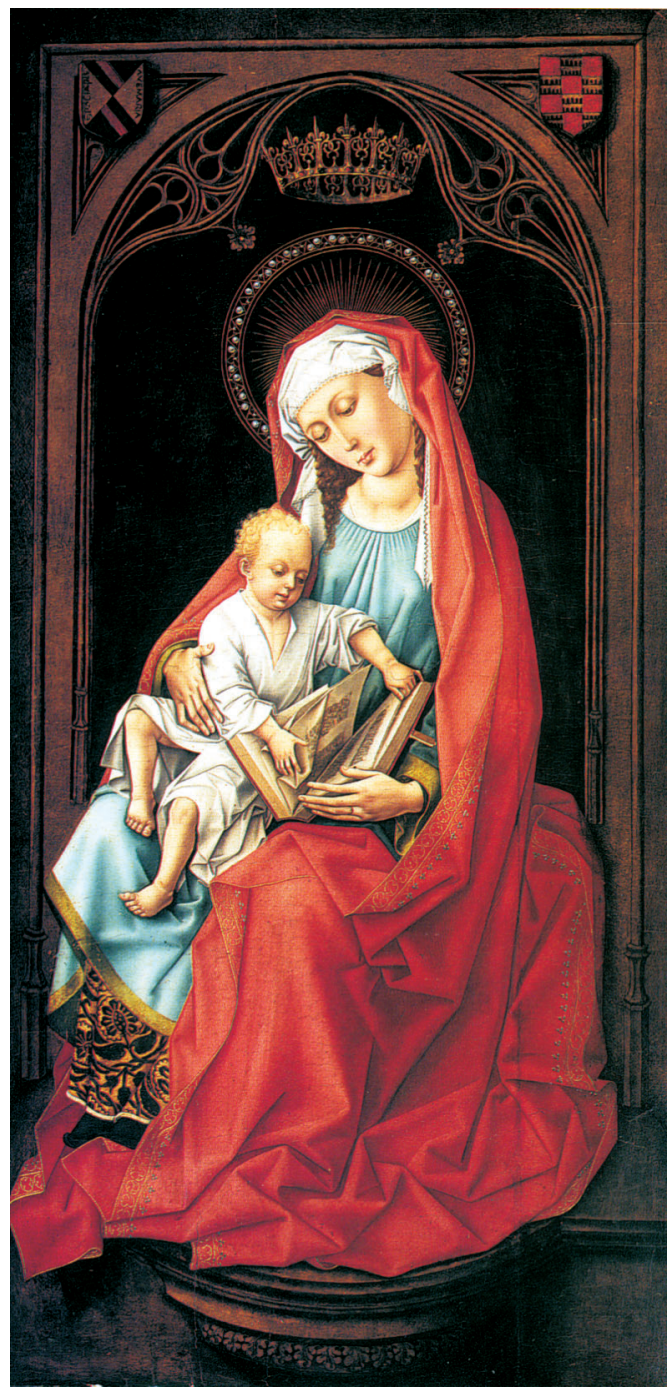

Fig. 7. Anónimo castellano, hacia 1500: copia de la Madona Durán; paradero actual desconocido (cliché Sotheby's, Londres).

Si la temprana difusión de la Madona Durán en España permite comprender cómo Bernart de Aras pudo tomarla como modelo en los años 1461-1463, el empleo de una fuente flamenca sorprende en un artista con un perfil tan manifiestamente local. Hemos visto cómo su actividad estaba fundamentalmente restringida a la zona de Huesca. Su estilo, además, sumerge sus raíces en la tradición aragonesa: según Post, el maestro habría recibido la influencia de otro maestro zaragozano, Martín de Soria, por el cual habría conocido el naturalismo gótico del catalán Jaime Huguet $^{26}$. En fin, si exceptuamos a la Virgen entronizada del retablo de Pompién, sus otras pinturas no presentan ningún rastro de influencia extranjera.

${ }^{26}$ Post, op. cit., 1941, p. 380. 
Su San Juan Bautista de pie (fig. 8), por ejemplo, procede de un modelo visiblemente aragonés en el que se inspiraron también el autor del retablo de la antigua colección Lafora de Madrid $^{27}$, Miguel Ximénez, en el retablo de Sijena conservado hoy en día en el Museu Nacional d'Art de Catalunya ${ }^{28}$ (fig. 9) y el anónimo que pintó las figuras de dos San Juan de la antigua colección Valenciano de Barcelona ${ }^{29}$ (fig. 10).

Hay que señalar que Aragón se abrió tardíamente al nuevo arte pictórico flamenco. Mientras que desde mediados del siglo XV ejemplares representativos de este arte tomaban rumbo a Castilla y al antiguo reino de Valencia ${ }^{30}$, como el ya citado tríptico de Miraflores de Rogier Van der Weyden (1445) o el San Jorge de Jan Van Eyck (1444), las pinturas flamencas para las cuales se admite una "procedencia" aragonesa parecen todas posteriores a 1490-1500. Se trata de obras pertenecientes o que pertenecieron al patrimonio eclesiástico local. Dos entre ellas han sido atribuidas de manera convincente al Maestro de Francfort: el tríptico de San Diego, procedente de Casbas (Huesca) ${ }^{31}$ y el del Museo de la Seo de Zaragoza ${ }^{32}$. A juzgar por su excepcional programa iconográfico, este segundo conjunto debe ser una obra de encargo, en todo caso posterior a 1512, ya que el pintor se ha inspirado en varios grabados de Durero, de los que los más tardíos, por ejemplo la Resurrección sobre cobre, llevan esa fecha. Señalar además que en el Tesoro de la Basílica del Pilar de Zaragoza se halla un Descendimiento de la Cruz de la escuela de Brujas, inspirado en Gerard David ${ }^{33}$, que la parroquia de Tauste (Zaragoza) posee una tabla con la Virgen y su Niño del taller de Gossaert ${ }^{34}$ y que en el Seminario Mayor de Belchite (Zaragoza) se conservaba, antes de la Guerra Civil, un retablo con puertas del Maestro del Tríptico Morrison ${ }^{35}$. Estas tres obras deben remontarse a los años 1510-1530. Finalmente, no podemos omitir, en este breve inventario de las tablas de Primitivos flamencos que pudieron llegar antiguamente a tierras aragonesas, tres pinturas del Museo de Zaragoza procedentes de instituciones religiosas de la ciudad o de la provincia. El San Jerónimo de Colyn de Coter se encontraba en la Cartuja de la Aula Dei; la Virgen con el Niño de un taller de Amberes en el convento de San Lamberto; en cuanto a la tabla atribuida tradicionalmente a Ambrosius Benson, pertenecía a la abadía cisterciense de Veruela ${ }^{36}$.

27 Vid., sobre esta obra, PosT, op. cit., 1941, pp. 23-25.

28 Vid., sobre esta obra, M. C. Lacarra Ducay, en Signos. Arte y cultura en el Alto Aragón medieval (cat. de exp.), Jaca, Catedral/Museo Diocesano y Huesca, Sala de Exposiciones/Sala Carderera, 1993, pp. 456-457; NAVAL MAs, op. cit., pp. 209-214.

29 Vid., sobre esta obra, GUDIOL RiCART, op. cit., 1971, n. ${ }^{\circ}$ C. 395.

$30 \mathrm{Vid}$., sobre la presencia de obras flamencas en Valencia, J. Gómez Frechina, "Algunas pautas flamencas en la pintura valenciana del siglo XV", en La clave flamenca en los Primitivos valencianos (cat. de exp.), Valencia, Museo de Bellas Artes, 2001, pp. 63-76.

31 Vid., sobre esta obra, E. Bertaux, Exposición retrospectiva de Arte.-1908, organizada bajo los auspicios del Excmo. Sr. Arzobispo de Zaragoza, Zaragoza/Paris, 1910, p. 93; S. H. GodDARD, The Master of Frankfurt and His Shop, Bruselas, 1984, n. 22.

32 Vid., sobre esta obra, Goddard, op. cit., n. ${ }^{\circ}$ 102; C. Morte García, en Aragón y la pintura del Renacimiento (cat. de exp.), Zaragoza, Museo e Instituto Camón Aznar, 1990, n. ${ }^{\circ} 45$; C. MorTe GArCíA, en El espejo de nuestra historia. La diócesis de Zaragoza a través de los siglos (cat. de exp.), Zaragoza, San Juan de los Panetes/Lonja/Palacio arzobispal, 1991-1992, p. 526; M. L. Herrero, en Reyes y mecenas. Los Reyes católicos, Maximiliano I y los inicios de la Casa de Austria en España (cat. de exp.), Toledo, Museo de Santa Cruz, 1992, n. ${ }^{\circ} 8$.

33 Vid., sobre esta obra, F. AbBad Ríos, Catálogo Monumental de España: Zaragoza, Madrid, 1957, p. 80 (fig. 320 , n. $\left.{ }^{\circ} 319\right)$.

34 Vid., sobre esta obra, C. Morte García, en Tesoros artísticos de la Villa de Tauste (cat. de exp.), Zaragoza, 2003, pp. 67-69.

35 Abbad Ríos, op. cit., p. 278; M. J. Friedländer, Early Netherlandish Painting VII: Quentin Massys, Leiden/ Bruselas, n. ${ }^{\circ} 82$.

36 Vid., sobre estas obras, M. L. Cancela Ramírez de Arellano y C. Gómez Dieste, "El Renacimiento, sala 16", Museo de Zaragoza. Guía, Zaragoza, 2003, p. 282. Vid., sobre la Madona de Veruela, en particular, C. Morte GarcíA, en Las tablas flamencas en la Ruta Jacobea (cat. de exp.), León (...), Sala Cultural Gaudí, 1999, n. ${ }^{\circ} 1$.

AEA, LXXXI, 321, ENERO-MARZO 2008, 1-16, ISSN: 0004-0428 


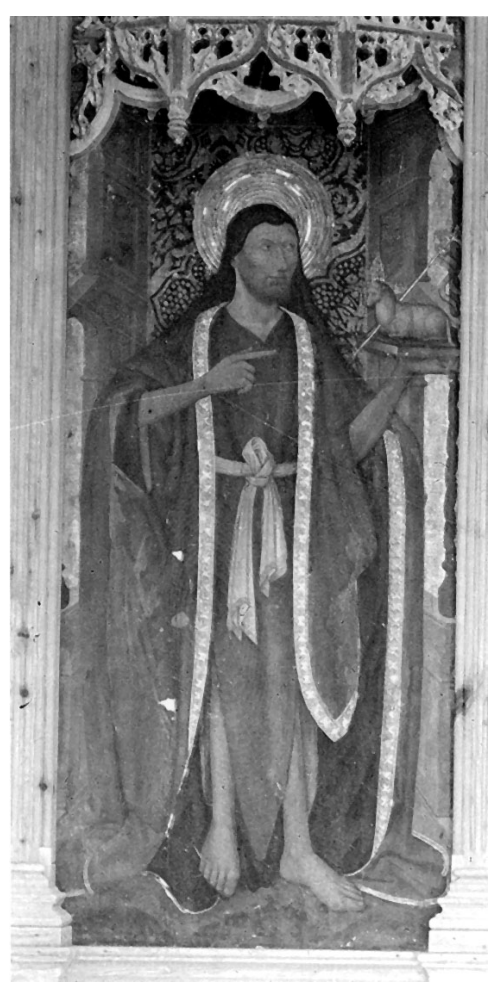

Fig. 8. Bernart de Aras: San Juan Bautista; paradero actual desconocido (cliché Mas, Barcelona).

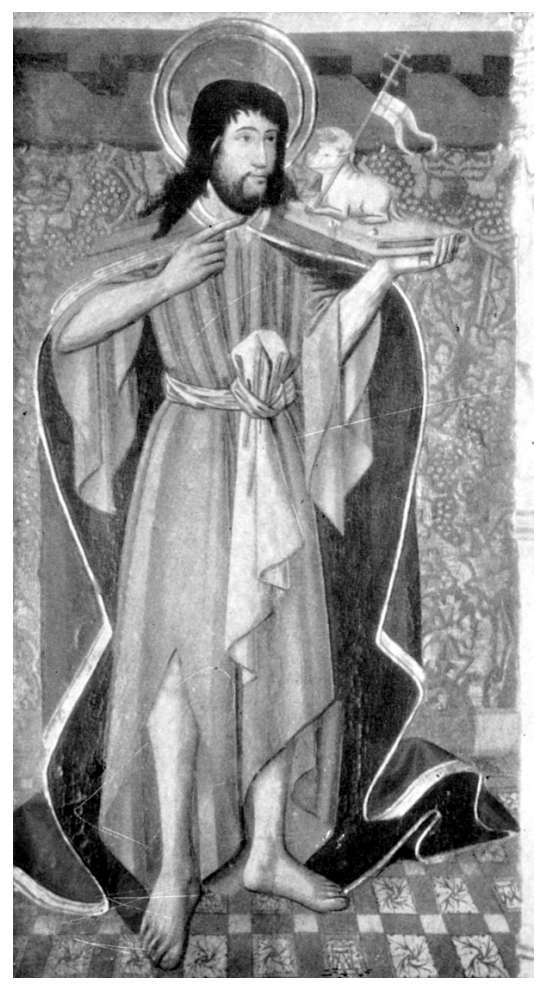

Fig. 10. Anónimo aragonés, hacia 1480-1500: San Juan Bautista: paradero actual desconocido.

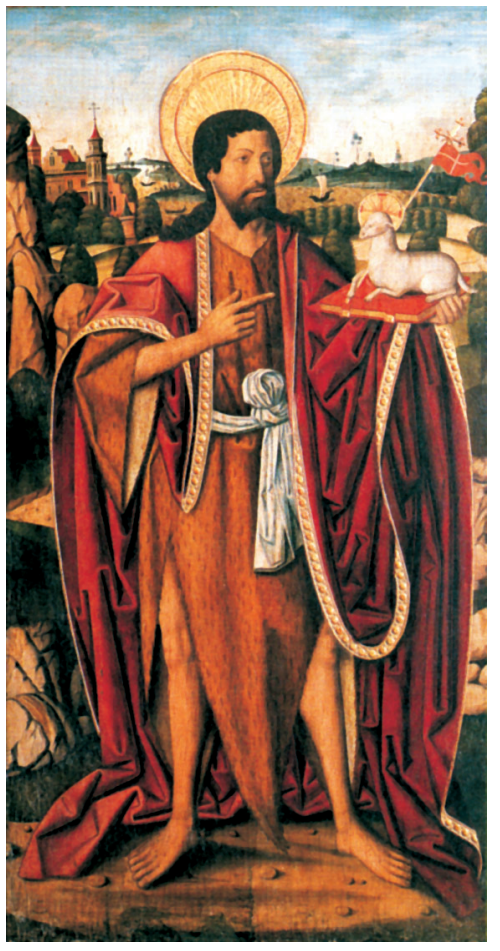

Fig. 9. Miguel Ximénez: San Juan Bautista; Barcelona, Museu Nacional d'Art de Catalunya (cliché museo). 
Ninguna de estas pinturas pudo realizarse antes de 1490-1500

Si la importación de pinturas flamencas en Aragón es, por lo tanto, posterior a la época del retablo de Pompién, lo mismo se puede decir de la estancia de Bartolomé Bermejo en esta región. Se considera generalmente que el gran virtuoso cordobés, tan profundamente marcado por los maestros de los antiguos Países Bajos, contribuyó de una manera decisiva a la difusión del naturalismo septentrional en Aragón ${ }^{38}$. Pero si Bermejo fue verdaderamente el origen de la moda "hispano-flamenca" que artistas locales, como Miguel Ximénez y Martín Bernat, intentaron prolongar después de su marcha, esta moda no se inicia antes del octavo decenio del siglo XV. Efectivamente, el maestro andaluz se habría establecido en Daroca a comienzos de los años setenta, probablemente un poco antes de 1474. En Zaragoza está documentado en 1477 y después, entre 1479 y $1484^{39}$, de una manera continua.

En la medida en que Bernart de Aras no parece haber querido rivalizar con los maestros septentrionales, es tentador considerar que la idea de reproducir la Madona Durán en la tabla principal del retablo de Pompién emanara no del artista, sino más bien del comitente. Sería el señor de Pompién, Gilbert Redón quien habría pedido al pintor tomar como modelo la tabla rogeriana. En los años 1460-1463, debía pertenecer a una familia importante de la nobleza española. Diversos indicios convergentes sugieren el nombre de los Mendoza. Hemos señalado que existe una copia de la Madona Durán, que se puede remontar a los años 1500 y que lleva las armas de esta familia. Además, el taller del Maestro de los Luna, que multiplicó las copias de la composición rogeriana en el último cuarto del siglo XV, trabajó para los Mendoza. Se atribuye de una manera convincente a este taller un retrato del cardenal don Pedro González de Mendoza flanqueado por cuatro personajes mitrados, retrato que formaba parte originalmente del retablo de San Ginés de Guadalajara ${ }^{40}$. El retablo de los Luna de la Catedral de Toledo, al cual el taller debe su denominación y que comporta numerosas citas tomadas de la Madona Durán, fue un encargo de María de Luna, cuyo marido, Íñigo López de Mendoza, era el segundo duque del Infantado. Asociada al nombre de los Mendoza, que en el siglo XV controlaban diversas plazas estratégicas de los reinos de Castilla y Aragón, la composición rogeriana pudo tener quizás un prestigio no sólo de naturaleza estética, sino también social, un prestigio del que el señor de Pompién habría estimado tener el derecho a disfrutar.

El retablo de Pompién presenta un interés tanto para el historiador de arte español como para el estudioso de la pintura de los antiguos Países Bajos. Ejemplo de traducción de un modelo pictórico flamenco a un idioma artístico local, la tabla de la Virgen entronizada confirma la existencia, desde mediados del siglo XV, de una verdadera conciencia estética aragonesa que 'filtra' de una manera sistemática las influencias exteriores. Será esta misma consciencia estética la que se apropriará con autoridad de las composiciones de Schongauer y las dotará de nimbos en relieve y de motivos decorativos mudéjares. Por otra parte, la Virgen entronizada de Bernart de Aras aporta nueva luz sobre una de las creaciones mayores de Rogier Van der Weyden, la

${ }^{37}$ He dejado de lado un tríptico flamenco del Museo de Huesca (BERMEJo MARTínEZ, op. cit., pp. 90-91) que puede atribuirse a un imitador del Maestro de Fráncfort. La obra fue donada al museo en 1873; se ignora su procedencia (información proporcionada por María de la Paz Cantero Paños, 27 enero 2006).

38 Vid. por ejemplo Post, op. cit., 1941, p. 6; M. Lacarra DucaY, en Arte gótico en el Museo de Zaragoza, Zaragoza, 2003, pp. 65-66.

39 Vid., sobre este tema, M. LACARra DuCAY, "Bartolomé Bermejo y su incidencia en el panorama artístico aragonés”, en La pintura gótica hispanoflamenca: Bartolomé Bermejo y su época (cat. de exp.), Barcelona (...), Museu Nacional d'Art de Catalunya (...), 2003, pp. 41-47.

40 Vid., sobre esta obra, S. ANDRÉs ORDAX, en Isabel la Católica. La magnificencia de un reinado (cat. de exp.), Valladolid (...), Monasterio de Nuestra Señora de Prado (...), 2004, n. ${ }^{\circ}$ 12. El autor pone claramente en evidencia las relaciones entre los Mendoza y el taller del Maestro de los Luna.

AEA, LXXXI, 321, ENERO-MARZO 2008, 1-16, ISSN: 0004-0428 
Madona Durán, en la medida en que acredita la hipótesis de su presencia en España incluso en vida de su autor.

En tales condiciones, sólo podemos lamentar que el retablo de Pompién tuviera que abandonar en 1936 el lugar para el cual fue concebido ${ }^{41}$. Desmantelado por orden de un capitán republicano, se habría puesto a resguardo en una caserna poco después de la Guerra Civil. Finalmente, en 1954, un oficial de mayor rango depositó cuatro tablas del conjunto en el Museu Nacional d'Art de Catalunya. La Madona entronizada no se encontraba entre ellas.

¿Dónde estará? Esperemos que no haya sido destruida y que el presente artículo pueda contribuir a su próxima reaparición.

Fecha de recepción: 24-I-2007

Fecha de aceptación: 16-VI-2007

41 Vid, para las informaciones aquí resumidas, NAVAL MAS, op. cit., p. 112. 